Matinlinna JP, Vallittu PK, Lassila LVJ. Effects of Different Silane Coupling Agent Monomers on Flexural Strength of an Experimental Filled Resin Composite. J Adhes Sci Techn 2011;45:179-192.

\title{
Effects of Different Silane Coupling Agent Monomers on Flexural Strength of an Experimental Filled Resin Composite
}

\author{
Jukka P. Matinlinna ${ }^{1^{*}}$, Pekka K. Vallittu ${ }^{2}$ and Lippo V. Lassila ${ }^{2}$ \\ ${ }^{1}$ The University of Hong Kong, Dental Materials Science, Faculty of Dentistry, Hong \\ Kong, P.R. China \\ ${ }^{2}$ The University of Turku, Prosthetic Dentistry and Biomaterials Science, Institute of \\ Dentistry, Turku, Finland
}

\footnotetext{
*To whom correspondence should be addressed.

E-mail: jpmat@hku.hk

tel: +85228590380

fax: +85225489464
} 


\section{Abstract}

The hydrolytic stability of various silane combinations and their effects on biomechanical properties and water sorption of an experimental dental composite made of bis-GMA and TEGDMA and silane-treated fillers were evaluated. Four silane coupling agents and their blends with a cross-linker silane were used as coupling agents for the $0.7-\mu \mathrm{m} \mathrm{BaSiO}_{3}$ fillers. The silanization was carried out in toluene containing $1 \%(\mathrm{v} / \mathrm{v})$ of one of the four following organofunctional silane coupling 3-acryloxypropyltrimethoxysilane, 3methacryloxypropyltrimethoxysilane, 3-styrylethyltrimethoxysilane, and 3isocyanatopropyltriethoxysilane. Blends of these functional silanes with $1 \%(\mathrm{v} / \mathrm{v})$ of a cross-linker silane, 1,2-bis-(triethoxysilyl)ethane were also used for silanization. Composites were prepared by mixing $5.00 \mathrm{~g}$ Ba-glass filler with $2.00 \mathrm{~g}$ of a resin mixture consisting of bis-GMA (58.8 wt-\%) and TEGDMA (39.2 wt-\%) in a highspeed mixer. Three-point bending test specimens $(2.0 \mathrm{~mm} \times 2.0 \mathrm{~mm} \times 25.0 \mathrm{~mm})$ were fabricated $(\mathrm{n}=8)$ in a mould and photo-polymerized. The degree of conversion was measured with FTIR. Biomechanical testing was carried out according to the ISO 10477 standard. Specimens were tested (flexural strength) after 30 days of water storage $\left(37^{\circ} \mathrm{C}\right.$, distilled water). Water sorption and solubility (in wt-\%) were also measured on $1,2,3,5,7,14,21$, and 30 days in water storage. Statistical analysis with ANOVA showed that the highest flexural strength was obtained when 3acryloxypropyltrimethoxysilane + 1,2-bis-(triethoxysilyl)ethane (100.5 MPa; SD, 25.7 $\mathrm{MPa}$ ) was used in the silanization step, and the lowest was obtained when 3isocyanatopropyltriethoxysilane + 1,2-bis-(triethoxysilyl)ethane (28.9 MPa; SD, 8.8 $\mathrm{MPa}$ ) was used. The three-point bending strength was significantly affected by the functionality of the main silane tested $(\mathrm{p}<0.05)$, but not by the addition of the cross- 
linker silane $(\mathrm{p}>0.05)$. The composite that had been silanized with 3isocyanatopropyltriethoxysilane had the greatest amount of water uptake (1.75\%), and the composite silanized with 3-methacryloxypropyltrimethoxysilane + 1,2-bis(triethoxysilyl)ethane had the least (1.08\%). In conclusion, selection of the functional silane monomer can be a significant factor in developing filled resin composites in dentistry.

Keywords: Silanization, silane coupling agent, biomechanical properties, filled resin, resin composite. 


\section{Introduction}

Silver amalgam is probably the oldest composite material used in dentistry: it has served as a convenient and durable direct restorative material for more than 160 years. However, amalgam is dark and thus not an esthetic material in the anterior region. Substantial efforts in the design and development of tooth-like materials have yielded silicate cement and glass ionomer cement. One of the main advances in dentistry in the 1960s was the use of unfilled polymer resin-based restoratives, and subsequently filled resins (resin composites) and related adhesive cements [1].

The poor wear resistance of early unfilled resins in dentistry owing to mechanical and physical problems was addressed through the incorporation of fillers, leading to a composite structure and thus reinforcement. Filled resins or resin composites are now indispensable in contemporary dentistry. Clinical applications include direct restorations with filling composites and indirect restorations with luting cements, as in the cementation of crowns, bridges, inlays, and onlays [2].

Water sorption is an unavoidable property of restoratives, and means to minimize water sorption are continually sought. A range of observed chemical, physical, and biomechanical deficiencies have also necessitated the development of new dental composites with superior biomechanical properties and durability. One conclusion is that there is no ideal solution to the problem and several compromises are usually involved [3]. Currently, fillers are used in nearly all composite structures in dentistry. E-glass fibers are also being increasingly used for reinforcement in modern dental biomaterials [4] that use blue light to initiate the setting reactions [5].

Reinforcements in the composite types mentioned always need silane coupling agents to enhance the adhesion of glass fillers (and E-glass fibers) to the polymer matrix [6-9]. It is widely accepted that adhesion between the glassy filler surface and 
silane is based on two main types of bonding: hydrogen bonds (such as $-\mathrm{OH} \cdots \mathrm{O}=$ ) and covalent siloxane bonds $(\equiv \mathrm{Si}-\mathrm{O}-\mathrm{Si} \equiv)$ at the glass-polymer matrix interface $[10]$. To turn silane alkoxy groups ( $\equiv \mathrm{Si}-\mathrm{O}-\mathrm{R})$ into labile, reactive silanol groups ( $\equiv \mathrm{Si}-\mathrm{OH})$, trialkoxysilane coupling agents with an organofunctional terminal group containing carbon-carbon double bonds $>\mathrm{C}=\mathrm{C}<$ are activated in alcohol-water solutions with a suitable catalyst [11]. They can also be activated in non-aqueous systems for special applications that require a water-free environment [12]. -

The methacrylate group is the most usually applied due to its reactivity and chemical compatibility with most resin systems, such as those based on bis-phenol-Adiglycidyldimethacrylate (bis-GMA), triethyleneglycoldimethacrylate (TEGDMA), and methylmethacrylate (MMA) [13-14]. These resin systems form an organic matrix by free radical polymerization of dimethacrylates, e.g. bis-GMA. Very recently, some less studied silane monomers have been reported to produce significantly higher shear bond strength results, suggesting that they could be useful for adhesion promotion [15-17].

The reported literature on the adhesion promotion behavior of trialkoxysilane monomers is scant, other than for 3-methacryloxypropyltrimethoxysilane in dental resin composites with spherical fillers. 3-Styrylethyltrimethoxysilane has previously been evaluated as a coupling agent for fillers in experimental nanocomposites [18]. Some less studied silanes have been evaluated as adhesion promoters in dentistry and have been reported to alter flexural strength and modulus of E-glass fibers in resinbased composites [4]. Moreover, the addition of a cross-linker silane to a silane blend (a novel silane system) enhanced these biomechanical properties [17].

The present study aimed to assess the in vitro biomechanical properties of an experimental filled resin composite constituted of bis-GMA and TEGDMA matrix 
and Ba-glass filler, after coupling using four organofunctional silane monomers, with or without a cross-linking silane monomer in an anhydrous medium, toluene. The hypothesis was that silane blends should result in higher flexural strength and lower water sorption than functional silanes only. Accordingly, the zero-hypothesis was that silanes alone or their blends promoted adhesion in experimental composites to the same degree and neither system lowered water sorption.

\section{Materials and Methods}

\subsection{Silane Monomers and Filler Silanization}

The silanes used for filler silanization were as follows: 3methacryloxypropyltrimethoxysilane (purity 98\%, Sigma-Aldrich Chemie GmbH, Steinheim, Germany; Lot S01603-022); 3-acryloxypropyltrimethoxysilane (95\%, Gelest, Morrisville, PA, USA; Lot 5C-6412); 3-styrylethyltrimethoxysilane (92\%, ABCR, Karlsruhe, Germany; Lot 7D-10467-S); and 3isocyanatopropyltriethoxysilane (95\%, Gelest, Morrisville, PA, USA; Lot 5I-7514). These silane monomers were also blended in a 1:1 ratio with a cross-linker silane, 1,2bis-(triethoxysilyl)ethane (Gelest, Morrisville, PA, USA; Lot 5L-7926). Silanes were used as received, without further purification by distillation (Figure 1).

Next, 5.00 g of Ba-glass filler (SP345; Specialty Glass, Oldsmar, FL, USA; Lot $0726031-79$ ) with a diameter of $0.7 \mu \mathrm{m}$ was added to a glass bowl containing a magnetic stirrer and $65 \mathrm{~mL}$ of water-free toluene (Sigma Aldrich, Steinheim, Germany). A $0.250-\mathrm{mL}$ aliquot of silane monomer (or $0.250 \mathrm{~mL}$ of functional silane $+0.250 \mathrm{~mL}$ cross-linker silane) was added to the bowl, and the contents were stirred for $23 \mathrm{~h}$ at room temperature. The toluene was decanted and the filler mixture was 
washed with $n$-hexane, decanted again, and allowed to dry in an oven at $60^{\circ} \mathrm{C}$ for $24 \mathrm{~h}$ [19]. The filler was then used to prepare the experimental composite specimens.

\subsection{The Resin System}

The experimental resin consisted of 58.8 wt- $\%$ bis-phenol-A diglycidyldimethacrylate, bis-GMA (Röhm, Darmstadt, Germany), 39.2 wt-\% triethyleneglycoldimethacrylate, TEGDMA (Sigma-Aldrich, Steinheim, Germany), 1.0 wt-\% 2-(dimethylamino)ethylmethacrylate, DMAEMA (Sigma-Aldrich, Steinheim, Germany) and 1.0 wt-\% camphorquinone (Fluka, Buchs, Switzerland). The resin was prepared in a polypropylene syringe covered with aluminum foil, and the syringe containing the resin was allowed to stabilize in the dark for $48 \mathrm{~h}$ before the next experimental step [4, 15-17].

\subsection{Experimental Composite Specimens}

A batch of filled resin composite mass was prepared by mixing $5.00 \mathrm{~g}$ of silanized filler and $2.00 \mathrm{~g}$ of resin matrix $(60 \%$ [w/w] bis-GMA, 40\% [w/w] TEGDMA) in a high-speed mixer (SpeedMixer DAC 150 FVZ-K; Hauschild, Hamm, Germany) at $1700 \mathrm{rpm}$ in two successive mixing periods of $30 \mathrm{~s}$, according to the manufacturer's instructions. The composite mass was protected from the light and stored in a refrigerator. The specimens were fabricated from this batch by placing an ample amount of composite into a stainless steel split mold with a brass frame and carefully filling the mold (total volume, $2.0 \mathrm{~mm} \times 2.0 \mathrm{~mm} \times 25.0 \mathrm{~mm}$, i.e. $100 \mathrm{~mm}^{3}$ ). Both the bottom and top of the mold were covered with a polyethylene foil (Transparent foil; Ivoclar, Schaan, Liechtenstein) [4, 17] to avoid any leakage of non-polymerized resin blend, according to the ISO Standard 10477:1992. There were 8 test specimens in 
each group, and each sample had a filler content of 71.4 mass-\%. A separate batch was used to fabricate one test group.

The experimental composite was light-polymerized with a halogen lamp handcuring unit (Model 100 Optilux; SDS Kerr, Danbury, CT, USA), with an average light intensity of $930 \mathrm{~mW} \mathrm{~cm}{ }^{-2}$ in the wavelength range of 400-505 $\mathrm{nm}$ and with a tip radius of $10 \mathrm{~mm}$. The light intensity was measured by the curing radiometer that was incorporated in the curing unit. The specimens were irradiated for $3 \times 40 \mathrm{~s}$ on both sides to ensure complete polymerization $[4,17]$. The degree of conversion of each composite sample was measured by Fourier transform infrared (FTIR) spectroscopy.

\subsection{Degree of Conversion}

The degree of conversion was measured with a Perkin Elmer Spectrum One FTIRspectrometer (Perkin-Elmer Ltd., Beaconsfield, UK) with an attenuated total reflectance (ATR) sampling accessory. The composite specimen was light-cured from the top. The measurements were made over a period of $15 \mathrm{~min}$ and specimens were scanned every $30 \mathrm{~s}$, with a resolution of $4.00 \mathrm{~cm}^{-1}$. Three measurements were made for each group. The degree of conversion, $\mathrm{DC} \%$, was calculated using the following formula [20]:

$$
D C \%=\left[1-\frac{C_{\text {aliphatic }} / C_{\text {aromatic }}}{U_{\text {aliphatic }} / U_{\text {aromatic }}}\right] \times 100
$$

In formula (1), $\mathrm{C}=$ aliphatic to aromatic peak ratio from the light-cured specimen and $\mathrm{U}=$ aliphatic to aromatic peak ratio from uncured specimen. 


\subsection{Storage Conditions (Aging) and Sorption Measurement}

Eight specimens were prepared from each resin-filler mixture. The specimens were then randomly divided into subgroups for different storage conditions: (a) storage at $37^{\circ} \mathrm{C} \pm 1{ }^{\circ} \mathrm{C}$ for 30 days, (b) water sorption group, and (c) solubility group. For group (b), each specimen's dry weight was measured and the specimens were stored in water for $1,2,3,6,7,14,21,31$ days $\left(37^{\circ} \mathrm{C}\right.$, distilled water) and reweighed. For group (c), specimens were weighed and stored in water for up to 30 days $\left(37^{\circ} \mathrm{C}\right.$, distilled water). At the storage time (in days) used for group (b), specimens were dried in an oven and weighed until their masses became constant.

\subsection{Flexural testing}

The flexural strength of the composite blocks was determined with the three-point bending strength test, performed according to the ISO 10477 standard. The composite specimens were also tested with a three-point loading test. The span between the supports was $20.0 \mathrm{~mm}$ and the crosshead speed during testing was $1.0 \mathrm{~mm} \mathrm{~min}^{-1}$. The load was applied with a universal testing machine (Lloyd LRX; Lloyd Instruments Ltd., Fareham, England) to the center-point of the test specimens (Figure 2). The deflection and load were recorded using Lloyd Nexygen 2.0 software program (Lloyd Instruments Ltd). The load at fracture of the test specimen was used to calculate the ultimate flexural strength $\left(\varepsilon_{\mathrm{F}}\right)$ and flexural modulus $\left(\mathrm{E}_{\mathrm{F}}\right)$, using the following formulas [20]:

$$
\begin{aligned}
& \varepsilon_{\mathrm{F}}=3 \mathrm{~F}_{\mathrm{m}} \mathrm{I} / 2 \mathrm{bh}^{2} \\
& \mathrm{E}_{\mathrm{F}}=\mathrm{SI}^{3} / 4 \mathrm{bh}^{3}
\end{aligned}
$$

In formula (2), $\mathrm{F}_{\mathrm{m}}$ is the applied load $(\mathrm{N})$ at the highest point of load-deflection curve, I is the span length $(20.0 \mathrm{~mm}), \mathrm{b}$ is the width of the test specimen $(\mathrm{mm})$ and $\mathrm{h}$ is the thickness of the test specimen (mm). In formula (3), $\mathrm{S}$ is the stiffness $(\mathrm{N} / \mathrm{m})$, and $\mathrm{S}=$ 
$\mathrm{F} / \mathrm{d}$ where $\mathrm{d}$ is the deflection $(\mathrm{mm})$ corresponding to load $\mathrm{F}(\mathrm{N})$ at a point in the straight-line portion of the trace.

\subsection{Statistical analysis of the results}

The flexural strength data and water uptake and solubility data were statistically analyzed using a three-way analysis of variance (ANOVA), using SPSS software, version 11.0 (Statistical Package for Statistical Science Inc., Chicago, IL, USA). The flexural strength was the dependent variable and the type of silane and the storage conditions were the independent factors. The level of statistical significance was set at $\mathrm{p}=0.05$, in other words $p$ values less than 0.05 were considered to be statistically significant in all tests (Figure 3).

\subsection{Scanning electron microscopy}

After flexural strength measurements, scanning electron microscopy (JSM 5500; JEOL, Tokyo, Japan) was used at a magnification of 1000x to examine the fractured surfaces of experimental composite specimens. An acceleration voltage of $14-18 \mathrm{kV}$ in vacuum was used, at a working distance of $20 \mathrm{~mm}$. The specimens were mounted on aluminum stubs and sputtered with gold (Unit E500; Polaron Equipment, Watford, UK) (Figure 4).

\section{Results}

Statistical analysis with ANOVA showed that the highest flexural strength was obtained when the 3-acryloxypropyltrimethoxysilane + 1,2-bis-(triethoxysilyl)ethane blend (100.5 MPa; SD, 25.7 MPa) was used in the silanization step. The lowest flexural strength was obtained when the 3-isocyanatopropyltriethoxysilane + 1,2-bis- 
(triethoxysilyl)ethane blend (28.9 MPa; SD, 8.8 MPa) was used The three-point bending strength was significantly affected by the functionality of the main silane tested $(\mathrm{p}<0.05)$, but not by the addition of the cross-linker silane $(\mathrm{p}>0.05)$ (Table $1)$.

The composite that had been silanized with 3-isocyanatopropyltriethoxysilane had the greatest amount of water uptake (1.75\%), whereas the sample silanized with 3methacryloxypropyltrimethoxysilane +1 ,2-bis-(triethoxysilyl)ethane $(1.08 \%)$ had the least. The solubility was the lowest for 3-styrylethyltrimethoxysilane $\left(0.19 \mathrm{mg} / \mathrm{mm}^{3}\right.$, and highest for 3-isocyanatopropyltriethoxysilane + 1,2-bis-(triethoxysilyl)ethane $\left(0.57 \mathrm{mg} / \mathrm{mm}^{3}\right)$ (Table 2$)$.

The degree of conversion, measured after taking three parallel FTIR measurements on samples, was found for experimental resin composite to be $59.6 \% \pm 2.4 \%$.

\section{Discussion}

The silane monomers were selected for this pilot study on the basis of some encouraging previous results, i.e. enhanced adhesion promotion, obtained for 3isocyanatopropyltriethoxysilane [21], 3-styrylethyltrimethoxysilane [18], and 3acryloxypropyltrimethoxysilane [15]. A silane blend system of a functional silane combined with a cross-linker silane has been reported to promote adhesion and protect against hydrolytic degradation in applications in production technology $[22,23]$. Recently in dental materials research, this blend has shown to promote adhesion of dimethacrylate resins onto silica-coated Ti [24] or zirconia [25], and to reinforce experimental E-glass fiber composite $[4,17]$. Thus, the expectation was that 
significantly higher changes would be observed after silanization with the blend than for silanization with 3-methacryloxypropyltrimethoxysilane alone, which is considered to be the gold standard $[10,11]$. The use of the cross-linking silane 1,2bis-(triethoxysilyl)ethane was also based on reported successful experiments [22-25]; however, this study was limited by the constant concentrations of the functional silane and the silanes in the blend.

Flexural strength, one of the key biomechanical properties of dental biomaterials, such as resin composites, is conventionally measured using a three-point bending test [20]. The maximum stress that is measured in the test is called the flexural strength. Statistical analysis showed that the highest flexural strength was obtained when 3-acryloxypropyltrimethoxysilane + 1,2-bis-(triethoxysilyl)ethane (100.5 MPa; SD, 25.7 MPa) was used (Table 1). Attention should also be given to the specimens silanized with 3-methacryloxypropyltrimethoxysilane and 3styrylethyltrimethoxysilane, which produced the highest numerical values. It should be noted that the addition of the cross-linker silane did not produce significant differences. Surprisingly, the use of 3-isocyanatopropyltriethoxysilane led to the lowest results in the study. This is contrary to results of a previous study in which silica-coated $\mathrm{Ti}$ was silanized with 1.0 vol\% solutions of 3isocyanatopropyltriethoxysilane and 3-methacryloxypropyltrimethoxysilane [21]; in that study dimethacrylate resin adhesion was significantly better after thermocycling, i.e. after the specimens had been subjected to thermal stress between $+5{ }^{\circ} \mathrm{C}$ and $55^{\circ} \mathrm{C}$ for 6000 cycles.

In general, water sorption should be low for resin composites, at 26 to 30 $\mu \mathrm{g} / \mathrm{mm}^{3}$, and the composite solubility should be between 0.25 and $2.5 \mathrm{mg} / \mathrm{mm}^{3}$ [26]. Because excessive water sorption has a detrimental effect on both color stability (not 
included in this research) and wear resistance (to be measured in the near future) [1], water sorption and composite solubility should be minimized. The results obtained concur well with specific values found in the literature. In this study, the results suggest that an addition of a cross-linker silane significantly reduces water uptake, but at the same time increases solubility (Figure 3, Table 2). So far, there have been no reports on resin composites of fillers silanized with silane blends, but elsewhere, silane blends have shown enhanced hydrolytic stability e.g. silanization pretreatment of galvanized steel $[22,23]$.

There was no statistically significant difference in solubility (i.e. the solubility of resin matrix) when the fillers were silanized with the silane blend or with the functional silane alone. Treatment with 3-isocyanatopropyltriethoxysilane gave distinctively different results from the other treatments, producing the lowest results, which suggests that the silanized fillers were not bonded strongly to the resin matrix and instead had been loosened out of the resinous monomer matrix. Interestingly, dental resin composite manufacturers do not reveal which silane coupling agent they have used in filler silanization. Yet, the stability and quality of the silane coupling agent (silane monomer) significantly affects solubility and water sorption $[1,26]$; hence, silane selection can be crucial. The use of a resin matrix is typical in dental materials because it exhibits lower polymerization shrinkage and more rapid polymerization than methylmethacrylate. Resin matrix is thus widely used in photopolymerizable resin systems [1,5], with 2-(dimethylamino)ethylmethacrylate as a plasticizer. In this study, we used the conventional bis-GMA/TEGDMA system. When compared with some other dimethacrylate systems, such as UEDMA (urethaneethyldimethacrylate) in combination with bis-EMA (an ethoxylated bisGMA), TEGDMA has been found to have the best plasticizing effect on bis-GMA 
[27]. The glass filler type used in this study also reflects typical practice. It is known to have adequate $\mathrm{X}$-ray opacity due to its $\mathrm{Ba}$ and $\mathrm{Si}$ content $[1,11,26]$. Filler silanization needs to take place in conditions that avoid extra humidity, such as in anhydrous, non-polar media [12]. For this reason, we selected toluene as the medium [19].

3-Styrylethyltrimethoxysilane has been recently reported to result in moderate improvement in flexural modulus compared with 3methacryloxypropyltrimethoxysilane and blends of the mentioned silanes [18]. Numerically, those results correspond with ours. The degree of conversion was typical of those usually observed for this type of bis-GMA/TEGDMA resin system composite $[1,26]$. In this study, we did not determine the linear coefficient of thermal expansion $(\alpha)$. It is known to be 25 to $38 \times 10^{-6}{ }^{\circ} \mathrm{C}^{-1}$ for multipurpose dental composites with a particle diameter of $0.2-3.0 \mu \mathrm{m}$ and a filler volume of $60 \%-70 \%$, increasing with the percentage of filler content [26]. We did not select any particular dental product as a resin composite control because there is a plethora of available potential products for which the literature gives comprehensive data.

\section{Conclusions.}

The results obtained suggest the following:

1. The hypothesis that silane blends should produce higher flexural strength and lower water sorption compared with functional silanes only was found to be valid.

2. Silanes alone and their blends do not promote adhesion to equal extents in the experimental composites and neither one lowers water sorption. 
3. Addition of a cross-linker silane to the filler silanization reduces water uptake for all silanes, but not significantly for all the silane blends.

4. Addition of a cross-linker silane during filler silanization enhances the solubility of resin composite.

\section{Acknowledgements}

This pilot study was financially supported by grants from The University of Hong Kong and The Finnish Dental Society Apollonia (Helsinki, Finland). We thank Dr. Barry Arkles (Gelest, Morrisville, PA, USA) for providing the silane monomers, Ms. Colleen Morrissette (Specialty Glass, Oldsmar, FL, USA) for providing the filler, and Dr. Trevor Lane (The University of Hong Kong) for proofreading the manuscript.

\section{References}

1. R van Noort. Introduction to Dental Materials. $3^{\text {rd }}$ Ed., Mosby Elsevier, Edinburgh, UK (2007).

2. J. F. Glenn, in: Biocompatibilty of Dental Materials, D.C. Smith and D. F. Williams (Eds.), pp. 97-130. CRC Press, Boca Raton, FL, USA (1982).

3. J. F. Roulet, Degradation of Dental Polymers, Karger, Basel, Switzerland (1987).

4. J. P. Matinlinna, J. E. Dahl, L. V. J. Lassila and P. K. Vallittu, in: Silanes and Other Coupling Agents, Vol. 4, K. L. Mittal (Ed.), pp. 83-97. VSP/Brill, Leiden (2007).

5. I. E. Ruyter and H. Oysaed, Acta Odont. Scand. 40, 179 (1982). 
6. K. L. Mittal (Ed.), Silanes and Other Coupling Agents, Vol. 5, VSP/Brill, Leiden (2009).

7. K. L. Mittal (Ed.), Silanes and Other Coupling Agents, Vol. 4, VSP/Brill, Leiden (2007).

8. K. L. Mittal (Ed.), Silanes and Other Coupling Agents, Vol. 3, VSP, Utrecht (2004).

9. K. L. Mittal (Ed.), Silanes and Other Coupling Agents, Vol. 2, VSP, Utrecht (2000).

10. M. R. Rosen, J. Coatings Technol. 50 (644), 70 (1978).

11. E. P. Plueddemann, Silane Coupling Agents, $2^{\text {nd }}$ Edn, Plenum Press, New York (1991).

12. T. M. Chen and G. M. Bauer, J. Dental Res. 61, 1439 (1982).

13. R. Labella, P. Lambrechts, B. van Meerbeek and G. Vanherle, J. Prosthet. Dentistry 15, 128 (1999)

14. A. H. Garcia, M. A. Lozano, J. C. Vila, A. B. Escribano and P. F. Galve, Med. Oral Pathol. Oral Cir. Bucal 11, 215 (2006).

15. J. P. Matinlinna, L. V. J. Lassila and P. K. Vallittu, Dental Mater. 23, 1173 (2007).

16. J. P. Matinlinna, T. Heikkinen, M. Özcan, L. V. J. Lassila and P. K. Vallittu, Dental Mater. 22, 824 (2006).

17. J. P. Matinlinna, J. E. Dahl, S. Karlsson, L. V. J. Lassila and P. K. Vallittu, in: Silanes and Other Coupling Agents, Vol. 5, K. L. Mittal (Ed.), pp. 107-121, VSP/Brill, Leiden (2009).

18. K. S. Wilson and J. M. Antonucci, Dental Mater. 22, 995 (2006).

19. K.-J. M. Soderholm and S. W. Shang, J. Dental Res. 72, 1050 (1993). 
20. ISO 10477-1992(E), Polymer-based crown and bridge materials.

21. J. P. Matinlinna, L. V. J. Lassila, I. Kangasniemi and P. K. Vallittu, J. Dental Res. 84, 360 (2005).

22. T. F. Child and W. J. van Ooij, Trans. Inst. Metal Finish. 77, 64 (1999).

23. A. Seth, W. J. van Ooij, P. Puomi, Z. Yin, A. Ashirgade, S. Bafna and C. Shivane, Progr. Org. Coat. 58, 136 (2007).

24. J. P. Matinlinna, L. V. J. Lassila and P. K. Vallittu, J. Dentistry 34, 740 (2006).

25. J. P. Matinlinna, L. V. J. Lassila and P. K. Vallittu Acta Odontol. Scand. 65, 44 (2007).

26. J. M. Powers and R. L. Sakaguchi, Craig's Restorative Dental Materials, $12^{\text {th }}$ Edn., Mosby Elsevier, St. Louis, MO (2006).

27. I. Sideriou, V. Tserki and G. Papanastasiou, Biomaterials 23, 1819 (2002). 


\section{Table 1.}

Silane(s) used and corresponding flexural strength and flexural modulus after the solubility test (30 days, the maximum storage time) of the experimental resin. Key: $\mathrm{SD}=$ standard deviation; ACPS $=$ Silanization with 3acryloxypropyltrimethoxysilane; ACPS + BTSE = 3-acryloxypropyltrimethoxysilane + 1,2-bis-(triethoxysilyl)ethane; MPS = 3-methacryloxypropyltrimethoxysilane;

MPS + BTSE = 3-methacryloxypropyltrimethoxysilane + 1,2-bis-

(triethoxysilyl)ethane; STYRX = 3-styrylethyltrimethoxysilane;

STYRX + BTSE = 3-styrylethyltrimethoxysilane + 1,2-bis-(triethoxysilyl)ethane; ICS

=3-isocyanatopropyltriethoxysilane; ICS $+\mathrm{BTSE}=3$ -

isocyanatopropyltriethoxysilane $+1,2$-bis-(triethoxysilyl)ethane.

\begin{tabular}{|l|l|l|l|l|}
\hline $\begin{array}{l}\text { Silane } \\
\text { used }\end{array}$ & $\begin{array}{l}\text { Flexural } \\
\text { Strength } \\
\text { / MPa }\end{array}$ & $\begin{array}{l}\text { SD / } \\
\mathrm{MPa}\end{array}$ & $\begin{array}{l}\text { Flexural } \\
\text { Modulus } \\
\text { / GPa }\end{array}$ & $\begin{array}{l}\text { SD / } \\
\text { GPa }\end{array}$ \\
\hline ACPS & 56.5 & 33.6 & 5.9 & 2.52 \\
\hline $\begin{array}{l}\text { ACPS }+ \\
\text { BTSE }\end{array}$ & 100.5 & 25.7 & 10.3 & 2.64 \\
\hline MPS & 83.2 & 23.7 & 6.4 & 1.14 \\
\hline $\begin{array}{l}\text { MPS }+ \\
\text { BTSE }\end{array}$ & 67.3 & 23.7 & 5.2 & 0.88 \\
\hline STYRX & 83.1 & 11.9 & 6.1 & 0.55 \\
\hline $\begin{array}{l}\text { STYRX } \\
+ \text { BTSE }\end{array}$ & 80.6 & 16.3 & 5.2 & 0.54 \\
\hline ICS & 38.0 & 6.9 & 5.3 & 0.60 \\
\hline $\begin{array}{l}\text { ICS + } \\
\text { BTSE }\end{array}$ & 28.9 & 8.8 & 4.1 & 0.76 \\
\hline
\end{tabular}


Table 2.

Silane(s) used and corresponding water uptake and solubility for the experimental resin. Key: $\mathrm{SD}=$ standard deviation; $\mathrm{m}($ soluble $)=$ mass that was dissolved. see also Table 1

\begin{tabular}{|l|l|l|l|l|l|l|l|l|l|l|}
\hline $\begin{array}{l}\text { Silane } \\
\text { used }\end{array}$ & $\begin{array}{l}\text { Water } \\
\text { uptake } \\
/ \%\end{array}$ & $\begin{array}{l}\text { SD } \\
\%\end{array}$ & $\begin{array}{l}\mathrm{m}(\text { water } \\
\text { uptake }) \\
/ \mathrm{g}\end{array}$ & $\begin{array}{l}\mathrm{SD} / \\
\mathrm{g}\end{array}$ & $\begin{array}{l}\text { Solubility } \\
/ \%\end{array}$ & $\begin{array}{l}\text { SD } \\
\%\end{array}$ & $\begin{array}{l}\mathrm{m} \text { (soluble) } \\
/ \mathrm{g}\end{array}$ & $\mathrm{SD} / \mathrm{g}$ & $\begin{array}{l}\text { Solubility } \\
\mathrm{mg} / \mathrm{mm}^{3}\end{array}$ & $\begin{array}{l}\text { SD } \\
\mathrm{mg} / \mathrm{mm}^{3}\end{array}$ \\
\hline ACPS & $1.27 \mathrm{a}$ & 0.04 & $0.089 \mathrm{a}$ & 0.004 & 0.28 & 0.03 & 0.020 & 0.002 & 0.20 & 0.02 \\
\hline $\begin{array}{l}\text { ACPS + } \\
\text { BTSE }\end{array}$ & $1.09 \mathrm{~b}$ & 0.08 & $0.076 \mathrm{~b}$ & 0.006 & 0.41 & 0.04 & 0.029 & 0.002 & 0.29 & 0.02 \\
\hline MPS & $1.24 \mathrm{a}$ & 0.06 & $0.087 \mathrm{a}$ & 0.005 & 0.32 & 0.05 & 0.022 & 0.003 & 0.22 & 0.03 \\
\hline $\begin{array}{l}\text { MPS + } \\
\text { BTSE }\end{array}$ & $1.08 \mathrm{~b}$ & 0.09 & $0.076 \mathrm{~b}$ & 0.007 & 0.38 & 0.04 & 0.027 & 0.003 & 0.27 & 0.03 \\
\hline STYRX & $1.22 \mathrm{a}$ & 0.06 & $0.085 \mathrm{a}$ & 0.005 & 0.27 & 0.03 & 0.019 & 0.002 & 0.19 & 0.02 \\
\hline $\begin{array}{l}\text { STYRX } \\
+ \text { BTSE }\end{array}$ & $1.12 \mathrm{a}$ & 0.08 & $0.078 \mathrm{a}$ & 0.006 & 0.32 & 0.04 & 0.022 & 0.003 & 0.22 & 0.03 \\
\hline ICS & 1.75 & 0.10 & 0.122 & 0.012 & 0.71 & 0.05 & 0.050 & 0.004 & 0.50 & 0.04 \\
\hline $\begin{array}{l}\text { ICS + } \\
\text { BTSE }\end{array}$ & 1.54 & 0.10 & 0.108 & 0.011 & 0.82 & 0.05 & 0.057 & 0.003 & 0.57 & 0.03 \\
\hline
\end{tabular}

$\mathrm{a}, \mathrm{b}=$ groups do not differ statistically significantly. $\mathrm{m}$ (soluble $)=$ mass that was dissolved 
<smiles>C=CC(=O)OCCC[Si](OC)(OC)OC</smiles>

a)<smiles>C=C(C)C(=O)OCCC[Si](OC)(OC)OC</smiles>

b)<smiles>C=Cc1ccc(CC[Si](OC)(OC)OC)cc1</smiles>

c)<smiles>CCO[Si](CCCN=C=O)(OCC)OCC</smiles>

d)<smiles>CCO[Si](CC[Si](OCC)(OCC)OCC)(OCC)OCC</smiles>

e) 
Figure 1. Structures of silanes used in the experimental composites: a) 3Acryloxypropyltrimethoxysilane, b) 3-Methacryloxypropyltrimethoxysilane, c) 3Styrylethyltrimethoxysilane, d) 3-Isocyanatopropyltriethoxysilane, e) 1,2-bis(Triethoxysilyl)ethane (the cross-linker silane).

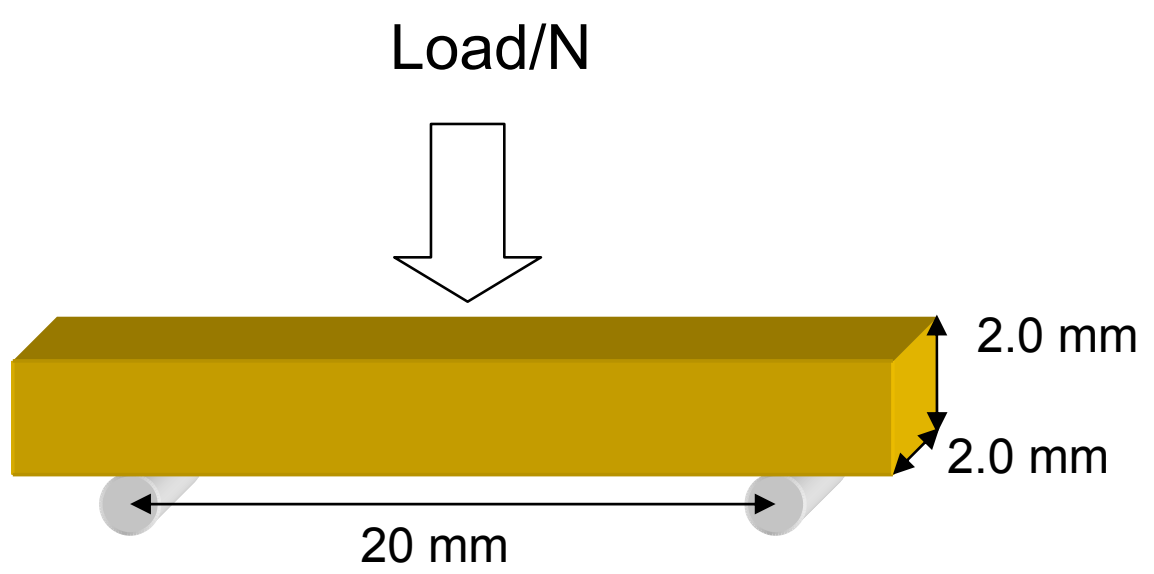

Figure 2. Schematic illustration of the set-up for the three-point flexural test with a rectangular resin composite test specimen. 


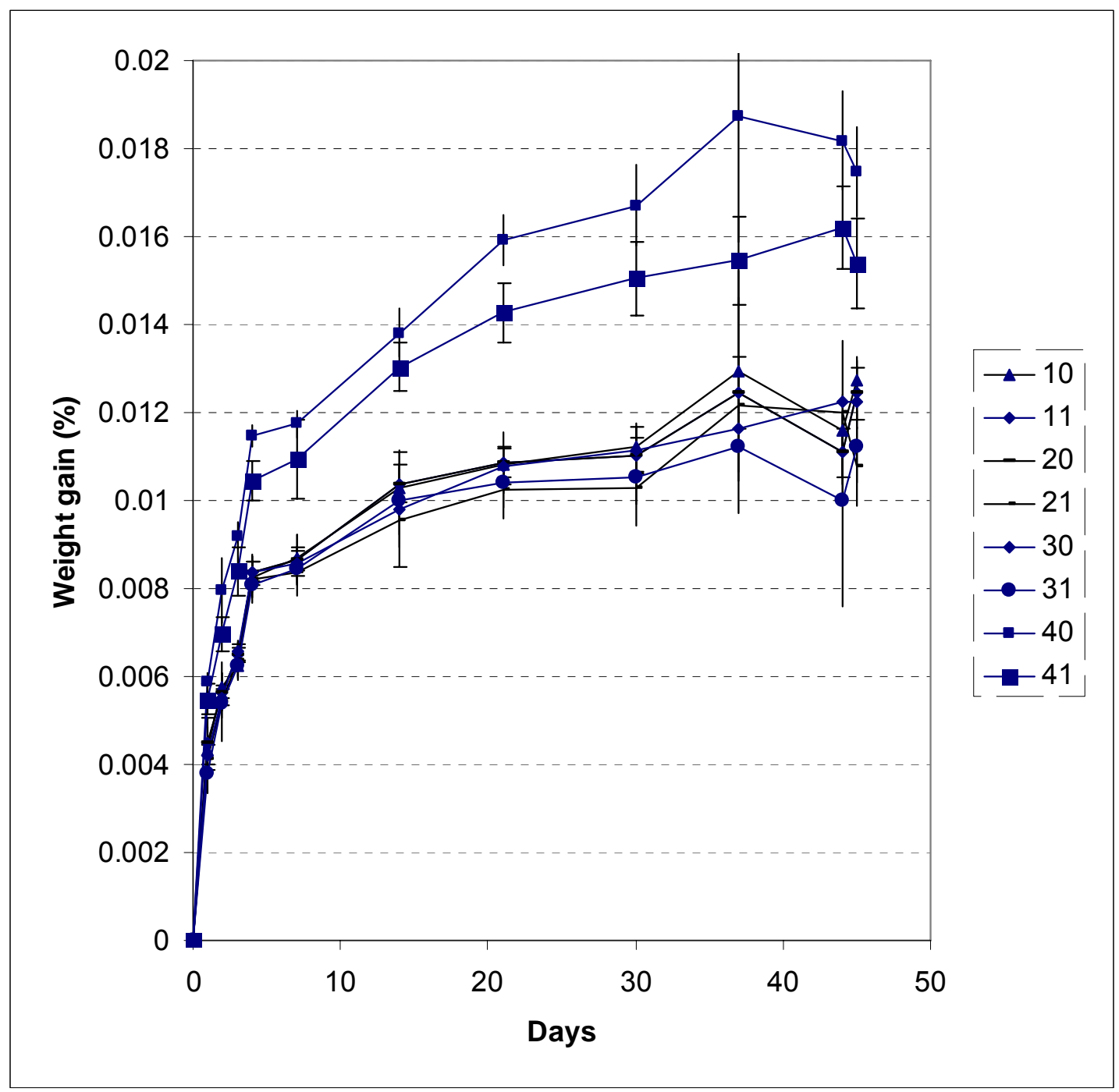

Figure 3. Water sorption of the experimental composite with different silanizations of the fillers. Key: $10=$ Silanization with 3-acryloxypropyltrimethoxysilane, $11=$ Silanization with 3-acryloxypropyltrimethoxysilane $+1,2$-bis(triethoxysilyl)ethane, $20=$ Silanization with 3-methacryloxypropyltrimethoxysilane, $21=$ Silanization with 3-methacryloxypropyltrimethoxysilane $+1,2$-bis(triethoxysilyl)ethane, $30=$ Silanization with 3-styrylethyltrimethoxysilane, 31 = Silanization with 3-styrylethyltrimethoxysilane + 1,2-bis-(triethoxysilyl)ethane, $40=$ Silanization with 3-isocyanatopropyltriethoxysilane and $41=$ Silanization with 3-isocyanatopropyltriethoxysilane + 1,2-bis(triethoxysilyl)ethane. 


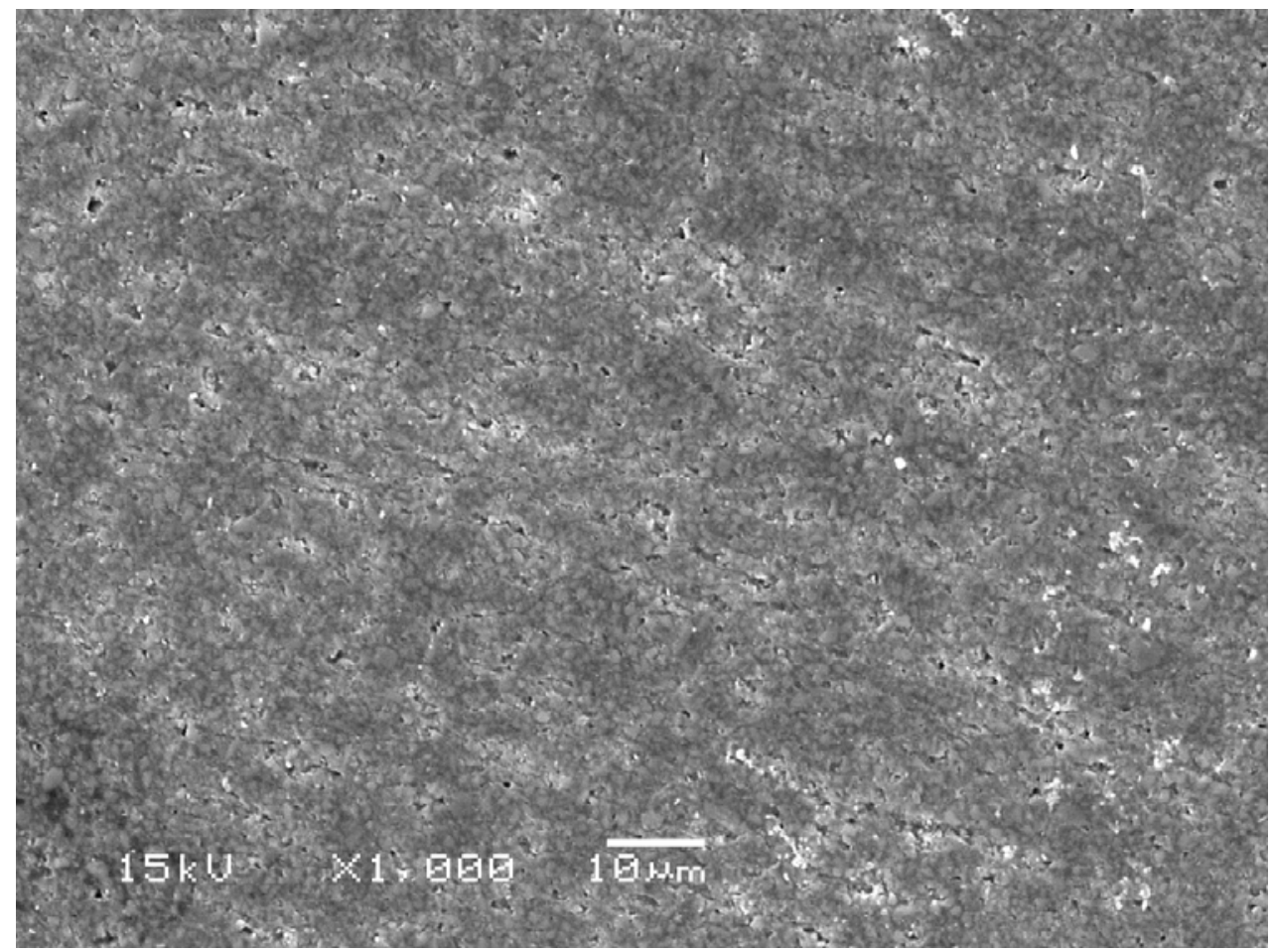

Figure 4: Composite specimens after water absorption and testing. a) Experimental composite with fillers silanized with 3-acryloxypropyltrimethoxysilane, (magnification $1000 \mathrm{x}$ ).

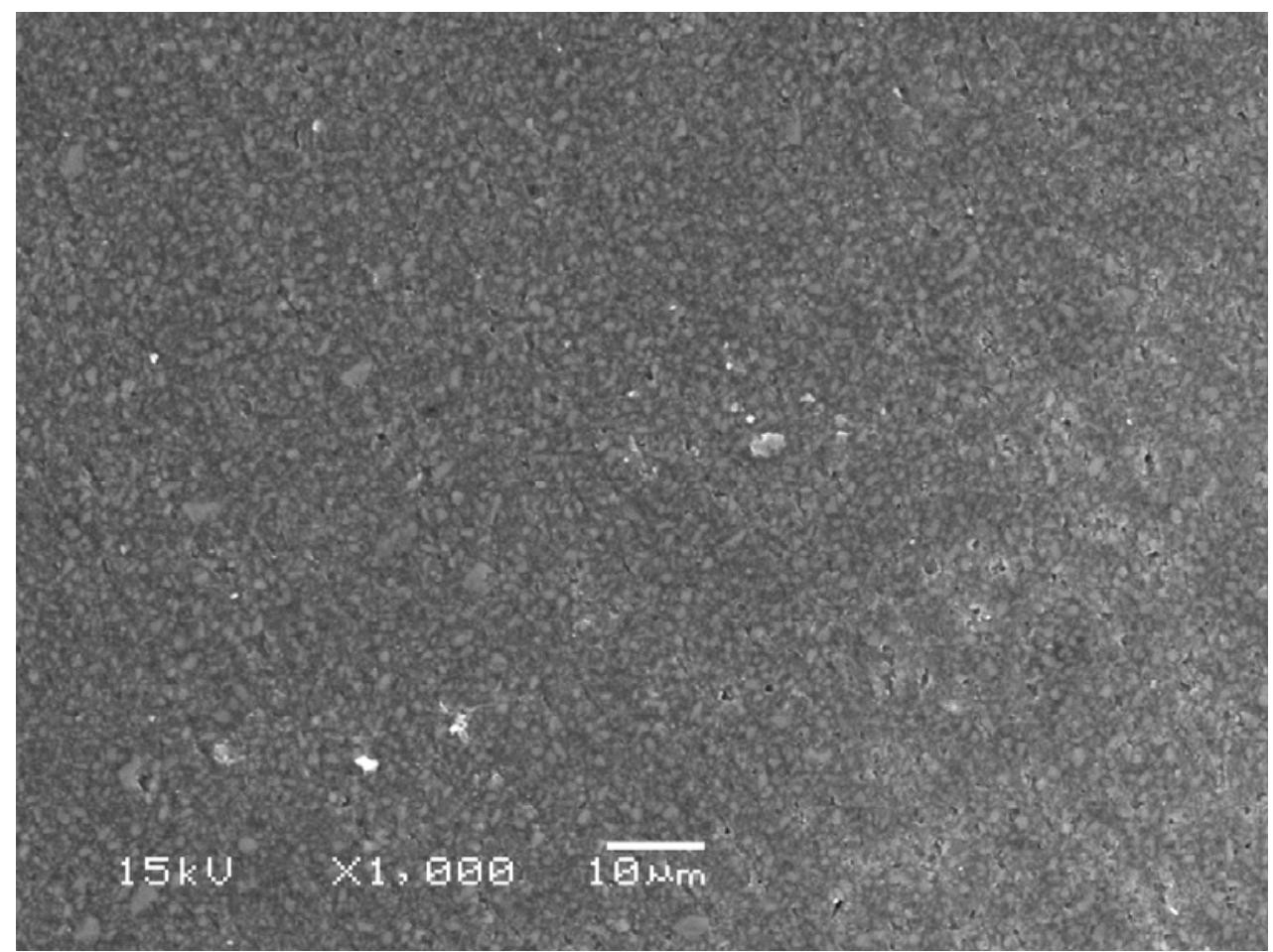

b) Experimental composite with fillers silanized with a blend of 3acryloxypropyltrimethoxysilane and 1,2-bis-(triethoxysilyl)ethane (magnification $1000 \mathrm{x})$. 


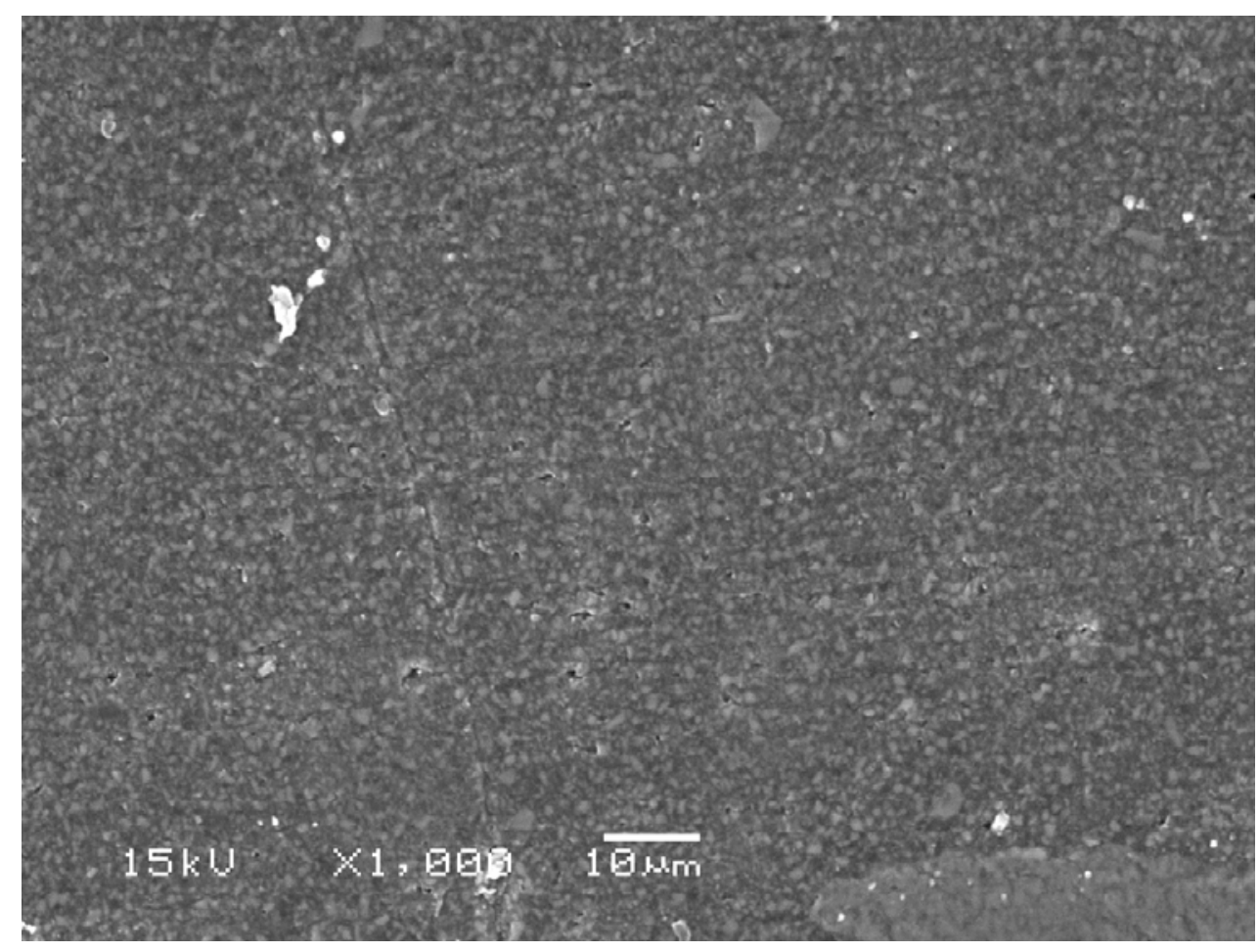

c) Experimental composite with fillers silanized with 3methacryloxypropyltrimethoxysilane, (magnification $1000 \mathrm{x}$ ).

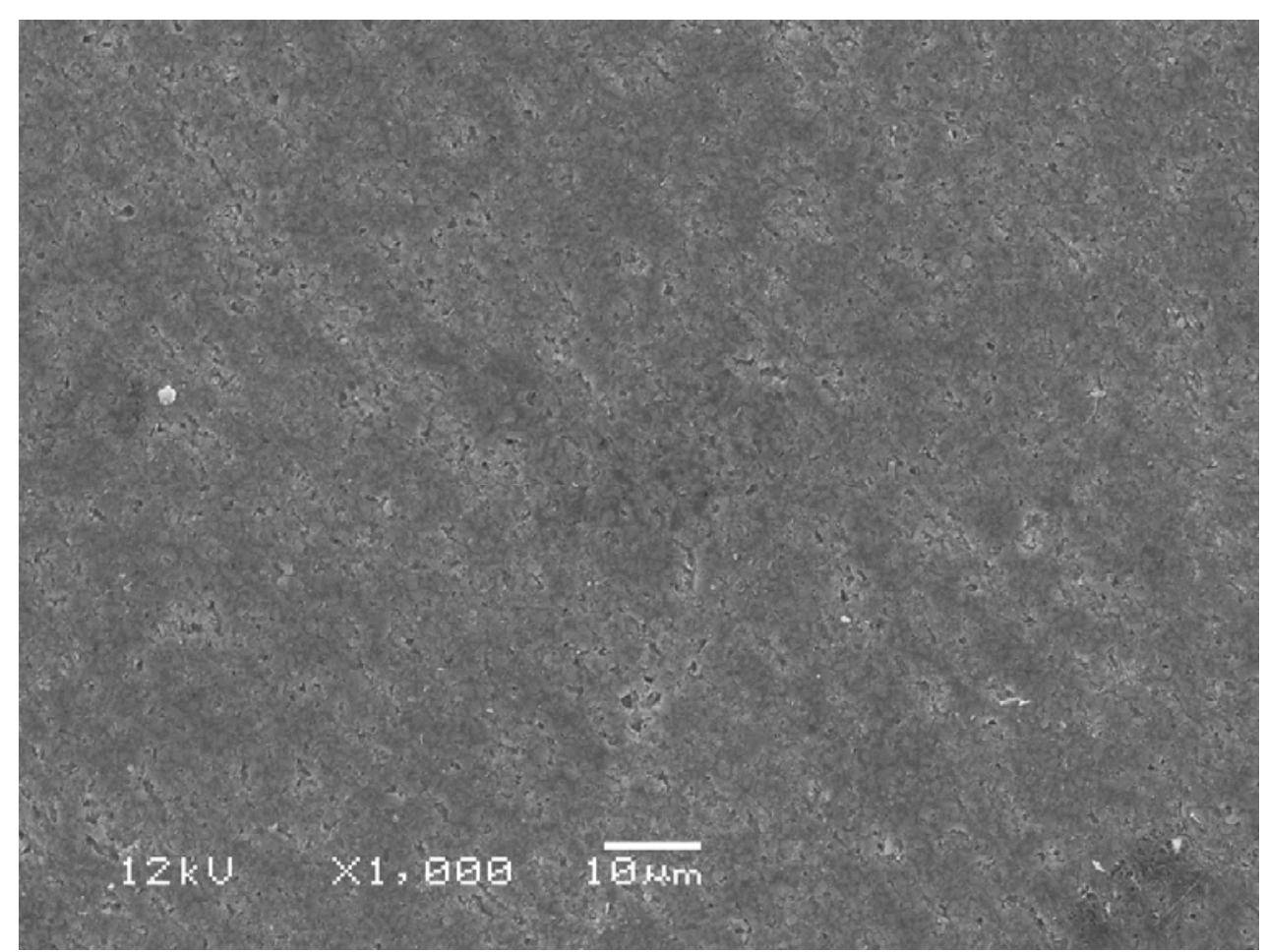

d) Experimental composite with fillers silanized with a blend of 3methacryloxypropyltrimethoxysilane and 1,2-bis-(triethoxysilyl)ethane (magnification $1000 \mathrm{x}$ ). 


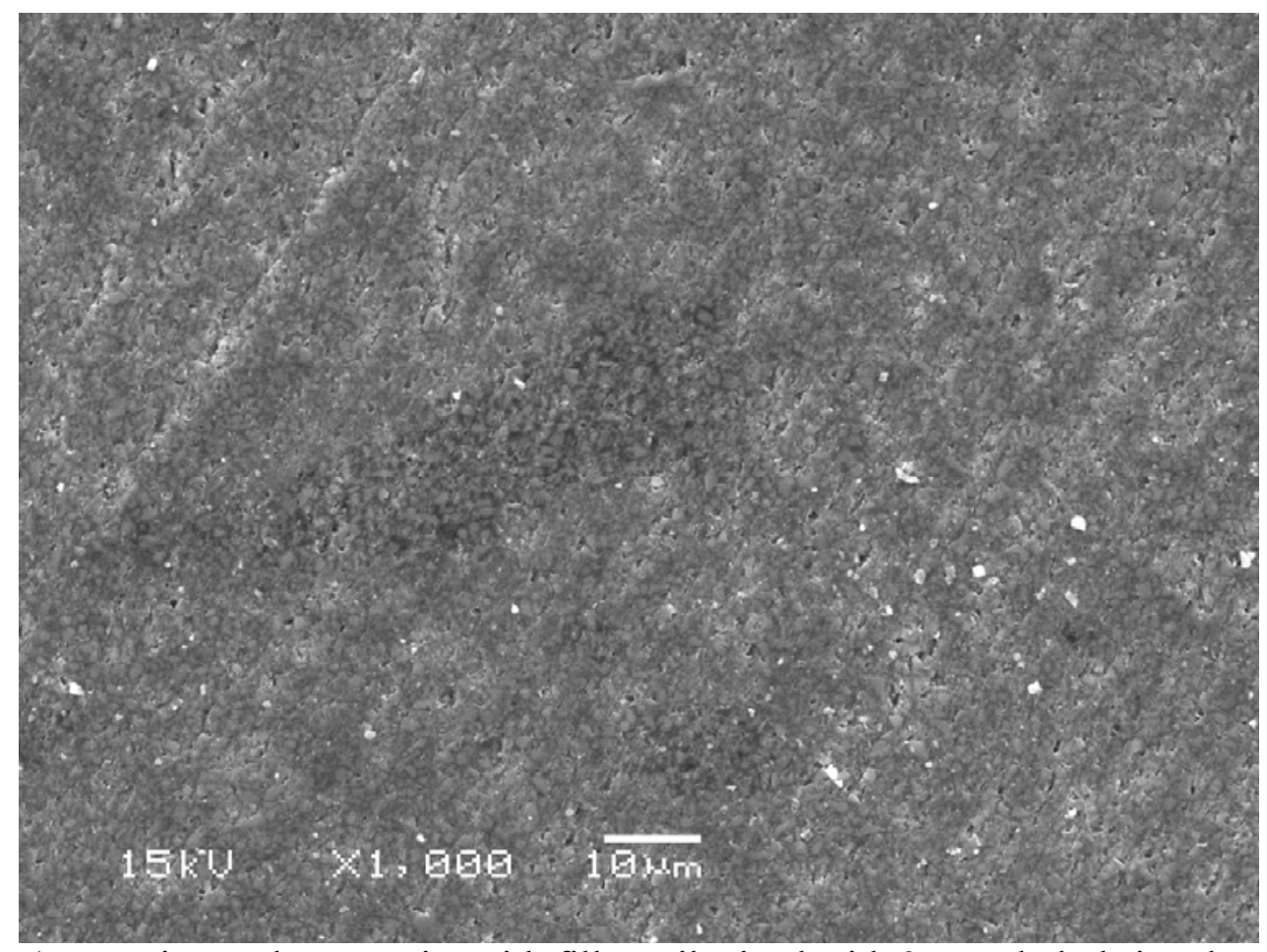

e) Experimental composite with fillers silanized with 3-styrylethyltrimethoxysilane (magnification $1000 \mathrm{x}$ ).

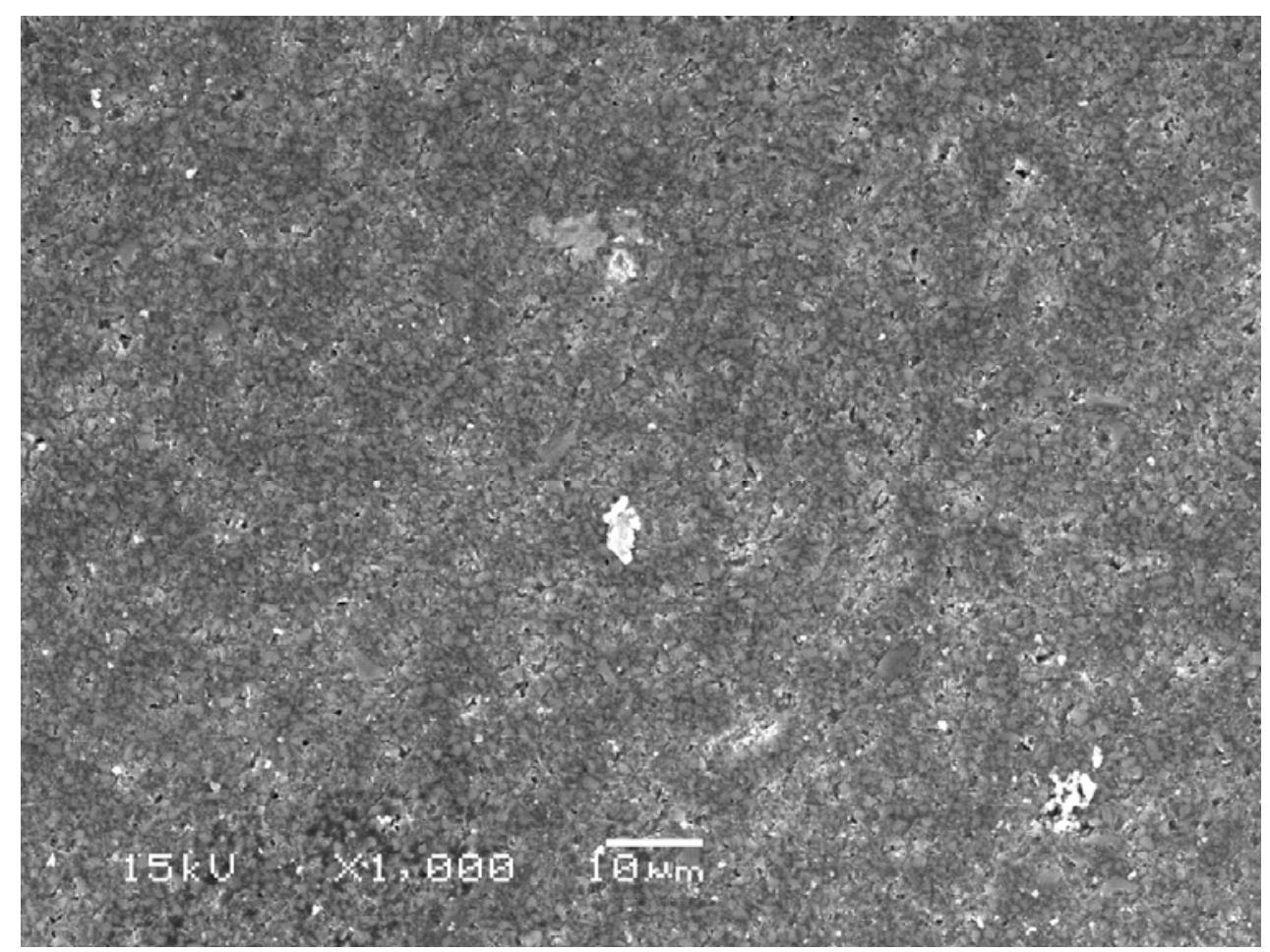

f) Experimental composite with fillers silanized with a blend of 3styrylethyltrimethoxysilane and 1,2-bis-(triethoxysilyl)ethane (magnification $1000 \mathrm{x}$ ). 


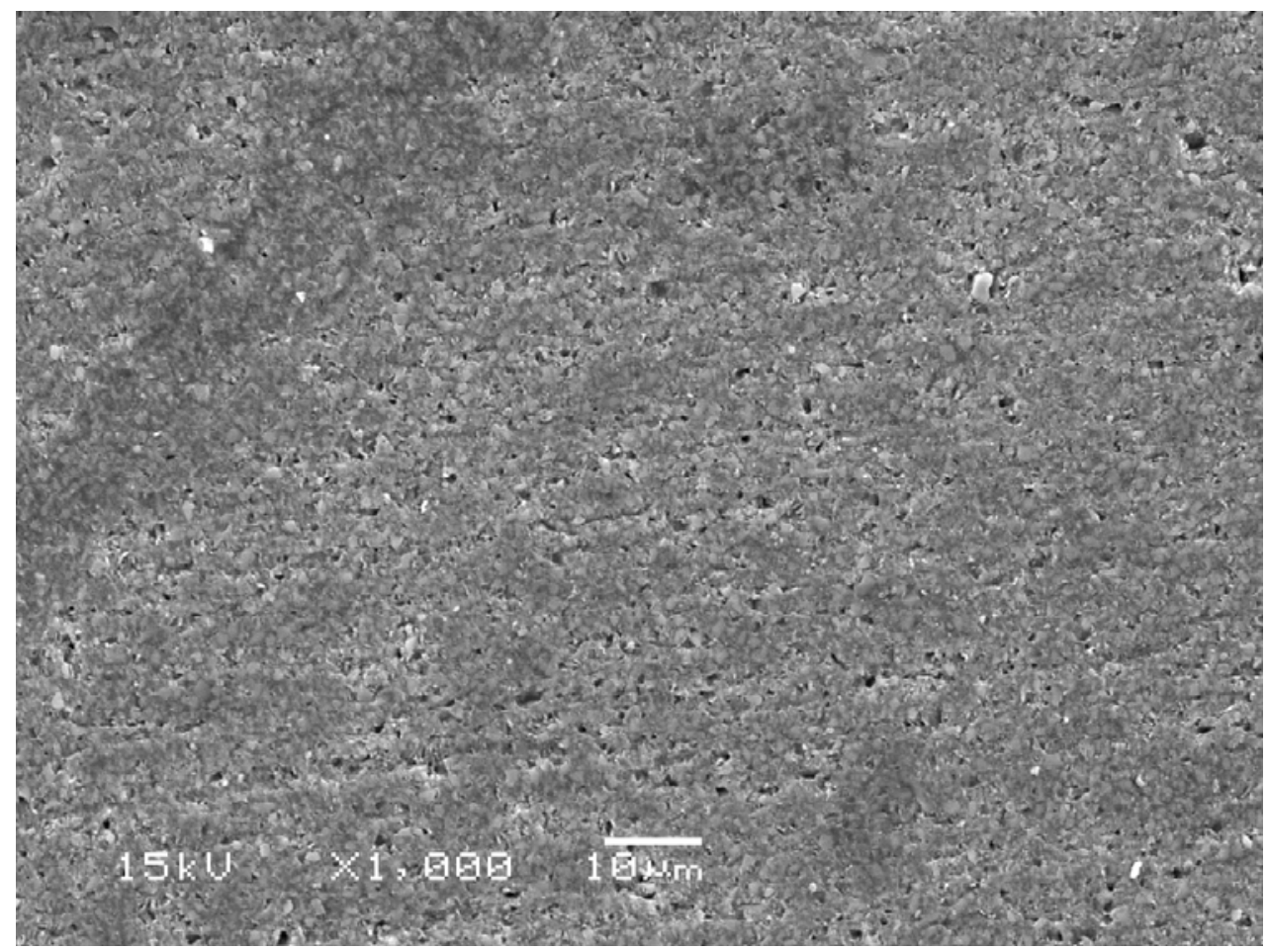

g) Experimental composite with fillers silanized with 3isocyanatopropyltriethoxysilane (magnification $1000 \mathrm{x}$ ).

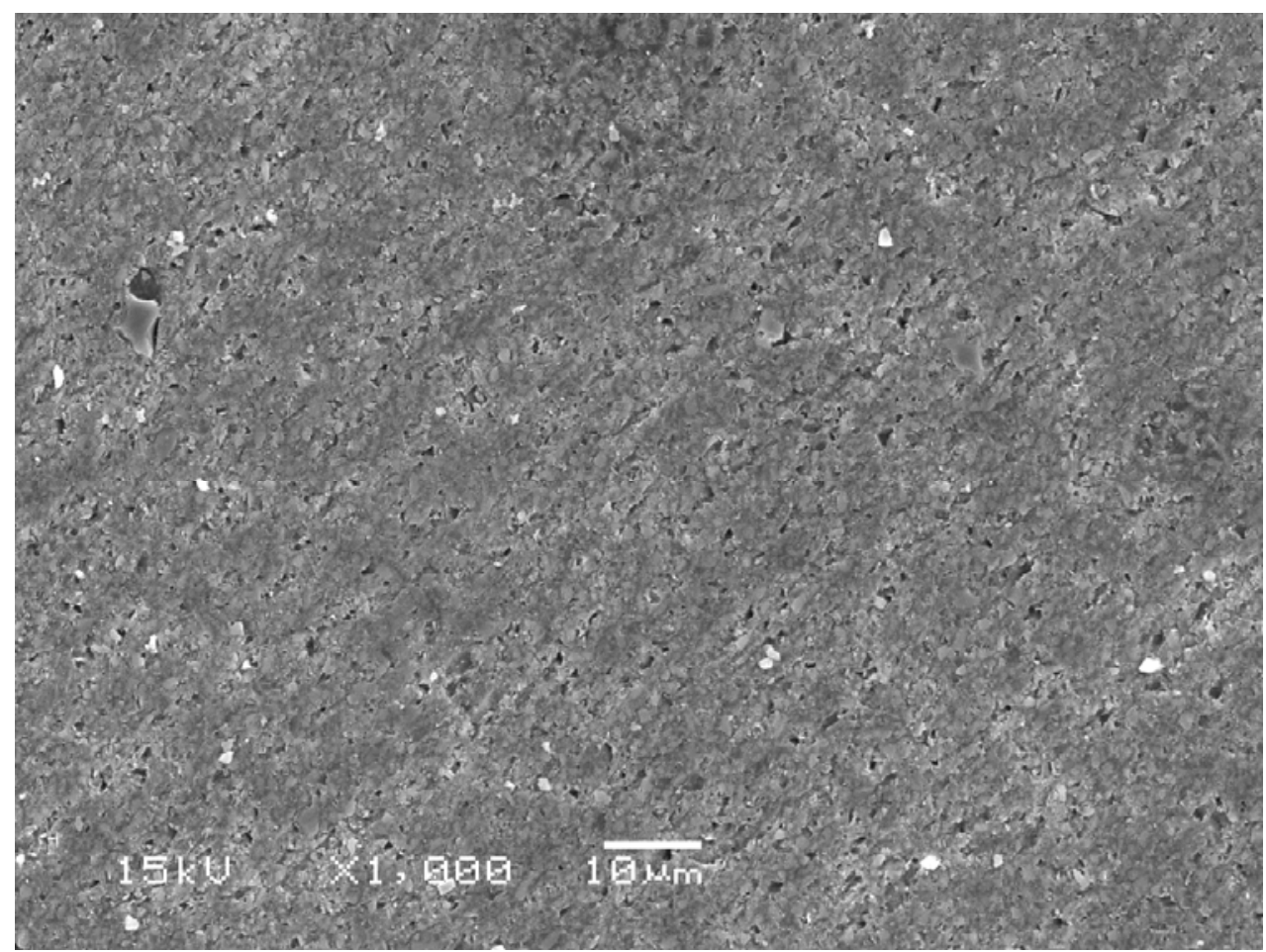

h) Experimental composite with fillers silanized with a blend of 3isocyanatopropyltriethoxysilane and 1,2-bis-(triethoxysilyl)ethane (magnification $1000 \mathrm{x})$. 